\title{
LIQUID-LIQUID EQUILIBRIA OF SYSTEMS CONTAINING PERFLUOROMETHYLCYCLOHEXANE
}

\author{
M.G. BERNARDO-GIL
}

Dep. Eng. Quimica, I.S.T., 1096 Lisboa Codex (Portugal)

\section{L.J.S. SOARES}

Universidade do Minho, L. Paço, 4719 Braga Codex (Portugal)

(Received July 1, 1988; accepted in final form June 29, 1990)

\section{ABSTRACT}

Bernardo-Gil, M.G. and Soares, L.J.S., 1990. Liquid-liquid equilibria of systems containing perfluoromethylcyclohexane. Fluid Phase Equilibria, 61: 121-130.

Liquid-liquid equilibria for the quaternary system perfluoromethylcyclohexane (PFMCH)-1-heptene-n-heptane-n-hexane at $288.15 \mathrm{~K}$ and for the ternary systems PFMCH-1-heptene-n-heptane, PFMCH-1-heptene-n-hexane and PFMCH-n-heptane-nhexane at $279.15 \mathrm{~K}$ and $288.15 \mathrm{~K}$ are reported.

The experimental results are compared with predicted values calculated using the NRTL and the UNIQUAC models.

\section{INTRODUCTION}

Multicomponent mixtures consisting of perfluorocarbons and hydrocarbons change swiftly from type to type pattern over a small temperature range. Following our experimental determination of binary solubility data for some perfluoromethylcyclohexane-hydrocarbon systems (Bernardo-Gil and Soares, 1988), this paper reports the results of measurements on liquid-liquid equilibrium for ternary and quaternary systems containing perfluoromethylcyclohexane (PFMCH), 1-heptene, n-heptane and n-hexane.

Predictions of equilibrium data for these mixtures were made using NRTL and UNIQUAC perfluoromethylcyclohexane-hydrocarbon parameters obtained from binary data. Hydrocarbon-hydrocarbon parameters were calculated by correlating the ternary data. The results are compared with the experimental ones.

0378-3812/90/\$03.50 C 1990 - Elsevier Science Publishers B.V. 
EXPERIMENTAL

\section{Materials}

PFMCH (Fluka, $\simeq 98 \%(G C)$ ), n-hexane, n-heptane (p. a., Merck) and 1-heptene (Fluka, $\approx 95 \%$ ) were used as supplied.

\section{Procedure}

The experimental work was carried out using a thermostatted miniature cell similar to that described by Soares et al. (1974). Temperature was measured within an accuracy of $0.01 \mathrm{~K}$ by means of a precision thermometer. The mixtures were stirred with a magnetic stirrer for at least $30 \mathrm{~min}$ and allowed to settle during a $4 \mathrm{~h}$ period. The tie-lines were obtained by analysing the compositions of the two conjugate phases in equilibrium by means of a gas chromatograph (Pye-Unicam) connected to an integrator (Varian CDS 111).

Calibration curves were obtained by using at least 10 mixtures of known composition, for which four to six chromatograms were obtained. Four to six samples of both phases were analysed to minimize the experimental error. The observation of the results shows also whether equilibrium has been reached.

TABLE 1

Experimental liquid-liquid equilibrium compositions for the ternary system PFMCH (1)-1heptene (2)-n-heptane (3)

\begin{tabular}{|c|c|c|c|c|}
\hline \multirow{2}{*}{$\begin{array}{l}\text { Temperature } \\
\text { (K) }\end{array}$} & \multicolumn{4}{|c|}{ Weight fraction } \\
\hline & $\overline{X_{11}}$ & $X_{31}$ & $X_{12}$ & $X_{32}$ \\
\hline \multirow[t]{6}{*}{279.15} & 0.9451 & 0.0159 & 0.2469 & 0.2200 \\
\hline & 0.9410 & 0.0239 & 0.2510 & 0.2988 \\
\hline & 0.9448 & 0.0242 & 0.2554 & 0.3320 \\
\hline & 0.9447 & 0.0298 & 0.2556 & 0.3910 \\
\hline & 0.9448 & 0.0362 & 0.2569 & 0.4609 \\
\hline & 0.9432 & 0.0402 & 0.2658 & 0.5362 \\
\hline \multirow[t]{8}{*}{288.15} & 0.9188 & 0.0716 & 0.3555 & 0.5567 \\
\hline & 0.9191 & 0.0686 & 0.3546 & 0.5294 \\
\hline & 0.9193 & 0.0601 & 0.3427 & 0.4753 \\
\hline & 0.9216 & 0.0425 & 0.3310 & 0.3586 \\
\hline & 0.9230 & 0.0338 & 0.3233 & 0.2960 \\
\hline & 0.9237 & 0.0266 & 0.3144 & 0.2422 \\
\hline & 0.9260 & 0.0217 & 0.3094 & 0.2069 \\
\hline & 0.9265 & 0.0135 & 0.3000 & 0.1250 \\
\hline
\end{tabular}


TABLE 2

Experimental liquid-liquid equilibrium compositions for the ternary system PFMCH (1)-1heptene (2)-n-hexane (3)

\begin{tabular}{lllll}
\hline Temperature & \multicolumn{3}{l}{ Weight fraction } & \\
\cline { 2 - 5 } & $X_{11}$ & $X_{31}$ & $X_{12}$ & $X_{32}$ \\
\hline 279.15 & 0.9042 & 0.0750 & 0.4143 & 0.4254 \\
& 0.9179 & 0.0519 & 0.3598 & 0.3602 \\
& 0.9268 & 0.0392 & 0.3348 & 0.3162 \\
& 0.9345 & 0.0280 & 0.3212 & 0.2502 \\
& 0.9390 & 0.0207 & 0.2917 & 0.1973 \\
& 0.9412 & 0.0128 & 0.2691 & 0.1272 \\
& 0.9158 & 0.0197 & 0.3399 & 0.1389 \\
& 0.9006 & 0.0330 & 0.3877 & 0.2113 \\
& 0.8969 & 0.0443 & 0.3902 & 0.2363 \\
& 0.8786 & 0.0660 & 0.4506 & 0.2732 \\
& 0.8593 & 0.0870 & 0.5024 & 0.2874 \\
& 0.8195 & 0.1252 & 0.6147 & 0.2579 \\
\hline
\end{tabular}

Tables 1-3 summarize the experimental results obtained for the ternary systems. Quaternary tie-line data are presented in Table 4.

\section{ANALYSIS OF RESULTS}

Prediction of ternary and quaternary liquid-liquid equilibrium data was realized using the well-known NRTL and UNIQUAC models proposed by

\section{TABLE 3}

Experimental liquid-liquid equilibrium compositions for the ternary system PFMCH (1)-nheptane (2)-n-hexane (3)

\begin{tabular}{lllll}
\hline Temperature & \multicolumn{4}{l}{ Weight fraction } \\
\cline { 2 - 5 } & $X_{11}$ & $X_{31}$ & $X_{12}$ & $X_{32}$ \\
\hline 279.15 & 0.8973 & 0.0812 & 0.4390 & 0.4208 \\
& 0.9094 & 0.0659 & 0.4091 & 0.3812 \\
& 0.9147 & 0.0550 & 0.3873 & 0.3521 \\
& 0.9239 & 0.0357 & 0.3482 & 0.2677 \\
& 0.9272 & 0.0268 & 0.3271 & 0.2199 \\
& 0.9324 & 0.0199 & 0.3136 & 0.1702 \\
& 0.9376 & 0.0098 & 0.2943 & 0.0968 \\
288.15 & 0.9083 & 0.0124 & 0.3968 & 0.0750 \\
& 0.8908 & 0.0352 & 0.4501 & 0.1600 \\
& 0.8669 & 0.0627 & 0.4968 & 0.2205 \\
& 0.8455 & 0.0865 & 0.5572 & 0.2350 \\
& 0.8226 & 0.1054 & 0.5942 & 0.2350 \\
\hline
\end{tabular}


TABLE 4

Experimental liquid-liquid equilibrium compositions for the quaternary system PFMCH (1)-1-heptene (2)-n-heptane (3)-n-hexane (4)

\begin{tabular}{lllllll}
\hline \multirow{2}{*}{$\begin{array}{l}\text { Temperature } \\
\text { K) }\end{array}$} & \multicolumn{6}{l}{ Weight fraction } \\
\cline { 2 - 6 } & $X_{11}$ & $X_{31}$ & $X_{41}$ & $X_{12}$ & $X_{32}$ & $X_{42}$ \\
\hline 288.15 & 0.9148 & 0.0134 & 0.0063 & 0.3201 & 0.1137 & 0.0457 \\
& 0.9095 & 0.0258 & 0.0115 & 0.3485 & 0.1897 & 0.0755 \\
& 0.8782 & 0.0213 & 0.0530 & 0.4485 & 0.1119 & 0.2252 \\
& 0.8421 & 0.0183 & 0.0982 & 0.5228 & 0.0676 & 0.2849 \\
& 0.8355 & 0.0436 & 0.0933 & 0.5360 & 0.1324 & 0.2643 \\
& 0.8848 & 0.0559 & 0.0412 & 0.4396 & 0.2820 & 0.1838 \\
& 0.9002 & 0.0390 & 0.0334 & 0.4014 & 0.2477 & 0.1772 \\
& 0.9048 & 0.0394 & 0.0207 & 0.3880 & 0.2653 & 0.1175 \\
& 0.8865 & 0.0354 & 0.0479 & 0.4484 & 0.1834 & 0.2082 \\
& 0.8627 & 0.0317 & 0.0784 & 0.5245 & 0.1163 & 0.2519 \\
& 0.8309 & 0.0302 & 0.1126 & 0.5925 & 0.0799 & 0.2582 \\
& 0.8677 & 0.0409 & 0.0767 & 0.5320 & 0.1561 & 0.2540 \\
0.8787 & 0.0491 & 0.0537 & 0.4751 & 0.2213 & 0.2106 \\
& 0.8892 & 0.0521 & 0.0378 & 0.4270 & 0.2773 & 0.1842 \\
& 0.8981 & 0.0519 & 0.0288 & 0.4162 & 0.3043 & 0.1498 \\
& 0.9063 & 0.0537 & 0.0179 & 0.3869 & 0.3585 & 0.1042 \\
& 0.9081 & 0.0574 & 0.0113 & 0.3748 & 0.3904 & 0.0697 \\
\hline
\end{tabular}

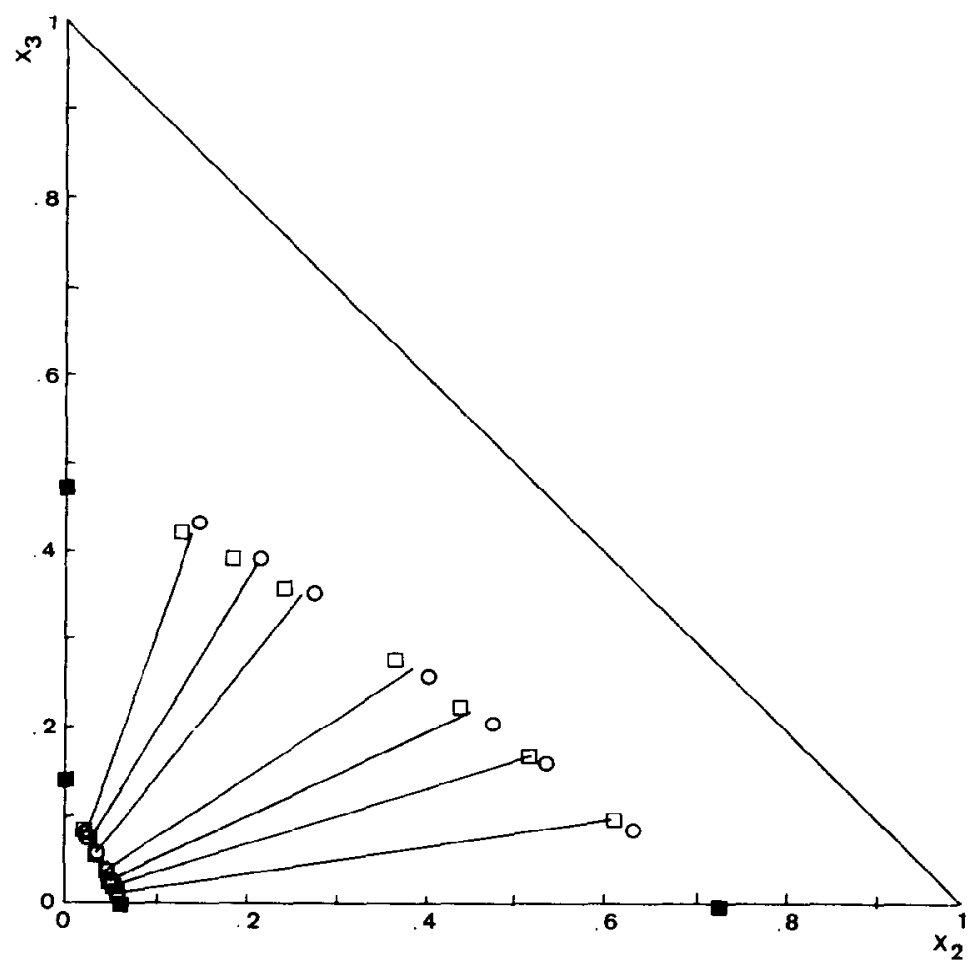

Fig. 1. Liquid-liquid equilibrium diagram for PFMCH-n-heptane-n-hexane at $279.15 \mathrm{~K}$ : (— $(-)$ experimental tie-lines; $(\square)$ binary data; $(\square)$ NRTL equation $\left(\alpha_{12}=0.3, \alpha_{13}=0.4\right.$, $\alpha_{23}=0.3$ ); (O) UNIQUAC equation. 
TABLE 5

Recommended values for the NRTL and UNIQUAC parameters at $279.15 \mathrm{~K}$ and $288.15 \mathrm{~K}$

\begin{tabular}{|c|c|c|c|c|c|c|}
\hline \multirow[t]{2}{*}{ System } & \multirow{2}{*}{$\begin{array}{l}T \\
(\mathrm{~K})\end{array}$} & \multicolumn{3}{|c|}{ NRTL } & \multicolumn{2}{|c|}{ UNIQUAC } \\
\hline & & $\overline{\alpha_{12}}$ & $\begin{array}{l}b_{12} \\
(\mathbf{K})\end{array}$ & $\begin{array}{l}b_{21} \\
(\mathbf{K})\end{array}$ & $\begin{array}{l}c_{12} \\
(\mathrm{~K})\end{array}$ & $\begin{array}{l}c_{21} \\
(\mathbf{K})\end{array}$ \\
\hline \multirow[t]{2}{*}{ PFMCH-n-hexane } & 279.15 & 0.4 & 392.1 & 545.1 & 131.0 & 3.579 \\
\hline & 288.15 & 0.4 & 347.5 & 462.8 & 147.4 & -20.53 \\
\hline \multirow[t]{2}{*}{ PFMCH-n-heptane } & 279.15 & 0.3 & 376.9 & 568.6 & 126.7 & 20.16 \\
\hline & 288.15 & 0.3 & 339.5 & 538.7 & 122.0 & 15.56 \\
\hline \multirow[t]{2}{*}{ PFMCH-1-heptene } & 279.15 & 0.3 & 387.9 & 602.1 & 141.1 & 18.02 \\
\hline & 288.15 & 0.3 & 343.6 & 600.0 & 124.4 & 24.24 \\
\hline
\end{tabular}

Renon and Prausnitz (1968) and by Abrams and Prausnitz (1975) respectively. Agreement between calculated and experimental data is expressed in terms of composition root-mean-square deviations (RMSD):

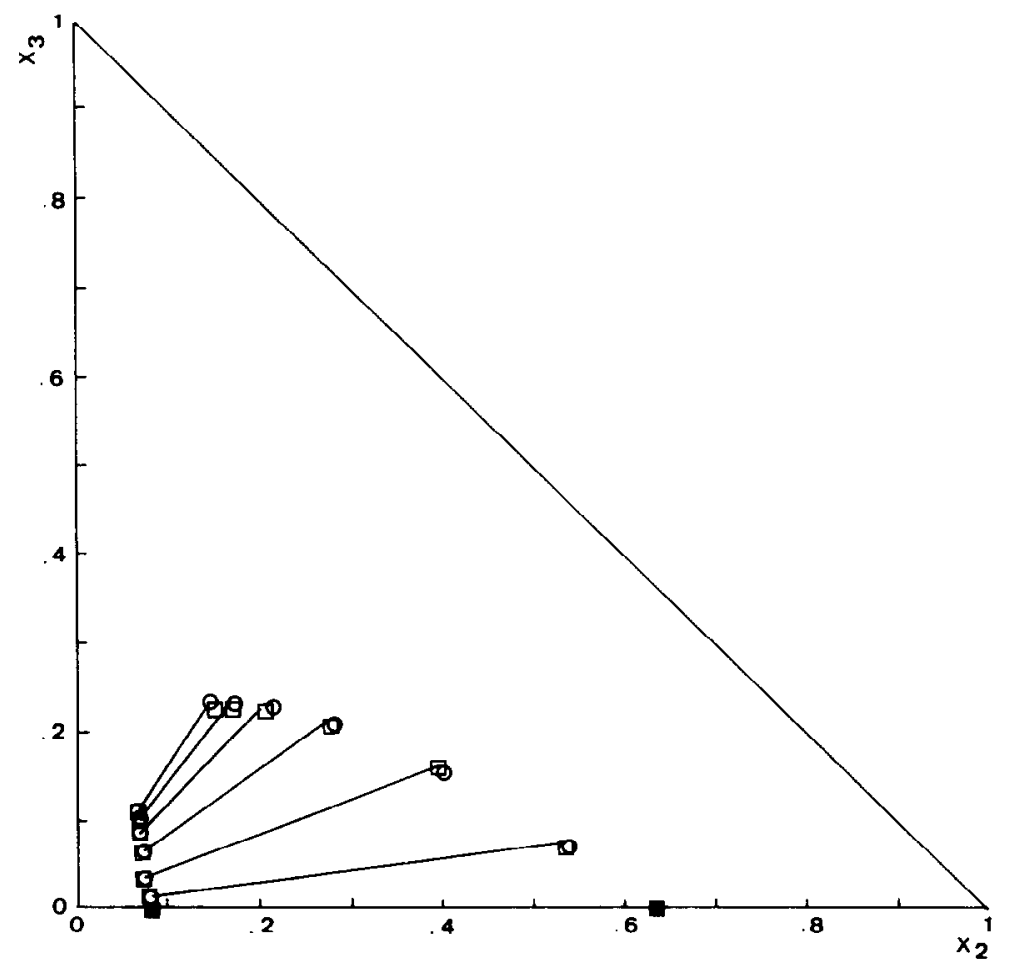

Fig. 2. Liquid-liquid equilibrium diagram for PFMCH-n-heptane-n-hexane at $288.15 \mathrm{~K}$. Symbols as in Fig. 1. 
TABLE 6

RMSD $\left(\times 10^{3}\right)$ between calculated and experimental values

\begin{tabular}{|c|c|c|c|c|c|c|}
\hline \multirow[t]{2}{*}{ System } & \multirow{2}{*}{$\begin{array}{l}T \\
(\mathrm{~K})\end{array}$} & \multirow[t]{2}{*}{ Type } & \multicolumn{2}{|c|}{ NRTL } & \multicolumn{2}{|c|}{ UNIQUAC } \\
\hline & & & $\overline{A^{a}}$ & $\mathrm{~B}^{\mathrm{b}}$ & $\overline{\mathrm{A}^{\mathrm{a}}}$ & $\overline{B^{b}}$ \\
\hline \multirow{2}{*}{$\begin{array}{l}\text { PFMCH-n-heptane- } \\
\text { n-hexane }\end{array}$} & 279.15 & II & 9.5 & 9.5 & 8.9 & 15.5 \\
\hline & 288.15 & I & 4.2 & 9.9 & 8.4 & 10.2 \\
\hline \multirow{2}{*}{$\begin{array}{l}\text { PFMCH-1-hleptene- } \\
\text { n-hexane }\end{array}$} & 279.15 & II & 7.8 & 8.7 & 7.8 & 7.8 \\
\hline & 288.15 & I & 12.8 & 14.3 & 17.2 & 17.2 \\
\hline \multirow{2}{*}{$\begin{array}{l}\text { PFMCH-1-heptene- } \\
\text { n-heptane }\end{array}$} & 279.15 & II & 9.7 & 10.8 & 9.6 & 11.3 \\
\hline & 288.15 & II & 4.7 & 5.2 & 4.2 & 4.4 \\
\hline $\begin{array}{l}\text { PFMCH-1-heptene- } \\
\text { n-heptane-n-hexane }\end{array}$ & 288.15 & II & 10.5 & 12.1 & 13.2 & 18.0 \\
\hline
\end{tabular}

A: Direct correlation of ternary data, keeping $\alpha_{i j}$ constant.

${ }^{b}$ B: For the PFMCH-hydrocarbon parameters the linear correlation with temperature was used. The hydrocarbon-hydrocarbon parametcrs were determined from the ternary data.

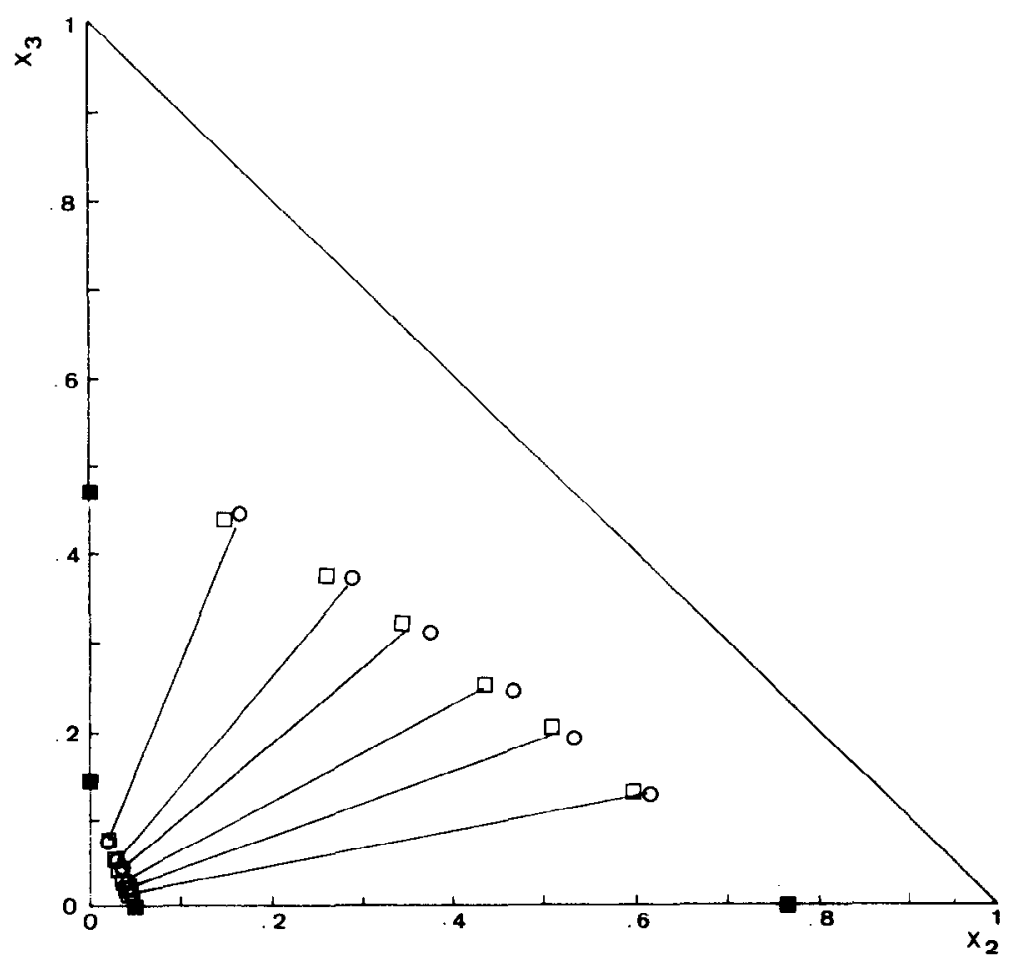

Fig. 3. Liquid-liquid equilibrium diagram for PFMCH-1-heptene-n-hexane at $279.15 \mathrm{~K}$. Symbols as in Fig. 1. 
$\mathrm{RMSD}=\left[\frac{\sum_{k}^{M} \sum_{i}^{N} \sum_{j}^{2}\left(x_{i j k}^{\mathrm{cal}}-x_{i j k}^{\exp }\right)^{2}}{2 N(M-1)}\right]^{1 / 2}$

Binary NRTL and UNIQUAC parameters were determined using two alternative approaches. Method A involved direct correlation of ternary data, the number of adjusted parameters varying from 1 to 6 , keeping $\alpha_{i j}$ constant ( 0.3 for hydrocarbon-hydrocarbon systems (Renon and Prausnitz, 1968) and the recommended values for PFMCH-hydrocarbon binaries (Bernardo-Gil and Soares, 1988)). In method B, for the PFMCH-hydrocarbon binaries, the linear temperature dependence of parameters obtained from the correlation of binary solubility data was used; hydrocarbon-hydrocarbon parameters were calculated adjusting ternary tie-line data.

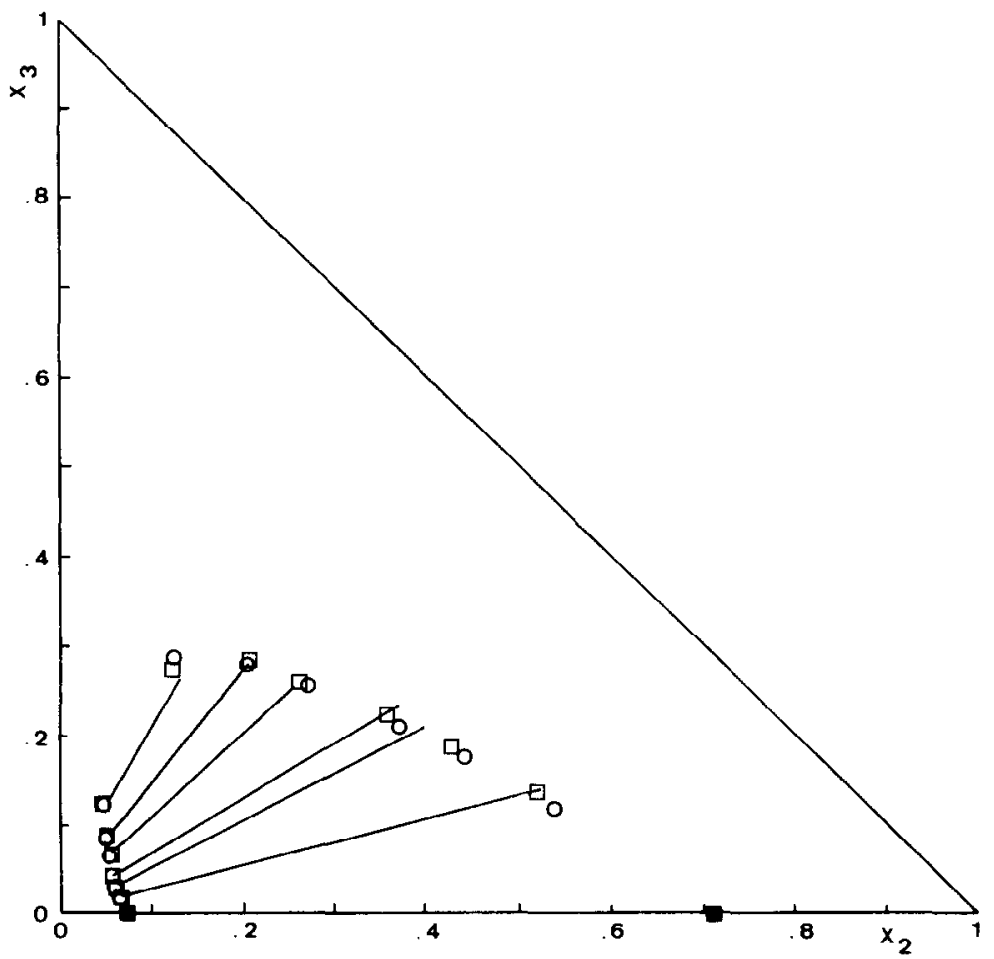

Fig. 4. Liquid-liquid equilibrium diagram for PFMCH-1-heptene-n-hexane at $288.15 \mathrm{~K}$. Symbols as in Fig. 1. 


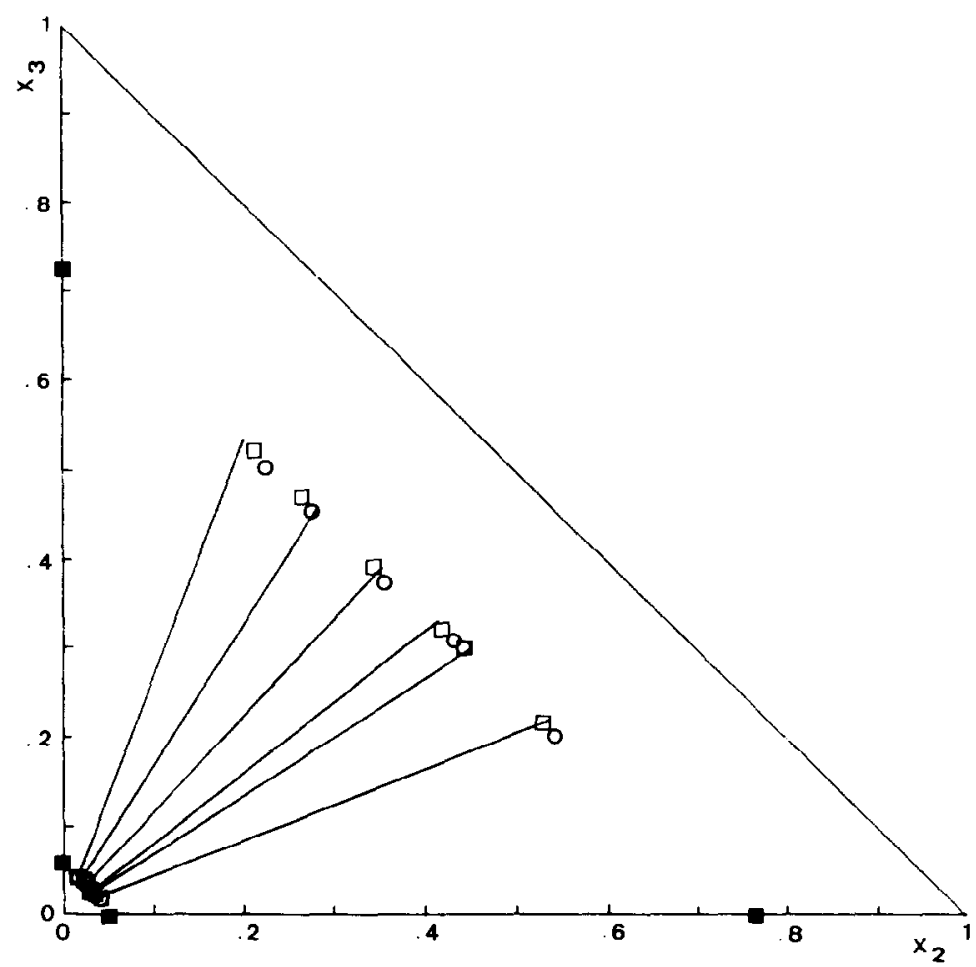

Fig. 5. Liquid-liquid equilibrium diagram for PFMCH-1-heptene-n-heptane at $279.15 \mathrm{~K}$ : $(\longrightarrow)$ experimental tie-lines; $(\square)$ binary data; ( $\square$ ) NRTL equation $\left(\alpha_{12}=0.3, \alpha_{13}=0.3\right.$, $\alpha_{23}=0.3$ ); (O) UNIQUAC equation.

Binary parameters from ternary data were calculated using the NelderMead method for the minimization of the following objective functions:

$$
\begin{aligned}
& F 1=\sum_{k}^{M} \sum_{i}^{N}\left[\ln \left(\gamma_{i 1} / \gamma_{i 2}\right)-\ln \left(x_{i 2} / x_{i 1}\right)\right]_{k}^{2} \\
& F 2=\sum_{k}^{M} \sum_{i}^{N} \sum_{j}^{2}\left(x_{i j k}^{\mathrm{cal}}-x_{i j k}^{\exp }\right)^{2}
\end{aligned}
$$

with $3 M>L, M$ being the available number of tie-lines, $N$ the number of components and $L$ the number of parameters.

The NRTL and UNIQUAC parameters recommended for the PFMCHhydrocarbon binaries are presented in Table 5 .

Table 6 shows the values of RMSDs between experimental and calculated compositions. Figures 1-6 represent the experimental and calculated tie-lines. 


\section{CONCLUSIONS}

The experimental results were correlated in terms of NRTL and UNIQUAC equations, which represent the binodal curves and the tie-lines correctly either for type I or type II systems.

With a slight loss of accuracy (relative to the results obtained from direct correlation of data for individual ternary systems) it is possible to obtain a set of NRTL and UNIQUAC parameters applicable to all multicomponent mixtures of PFMCH and hydrocarbons.

The overall results are better for the NRTL equation with use of recommended values of $\alpha_{i j}$, although the predicted multicomponent data are strongly dependent on the selected $\alpha_{i j}$ for the partially miscible binaries.

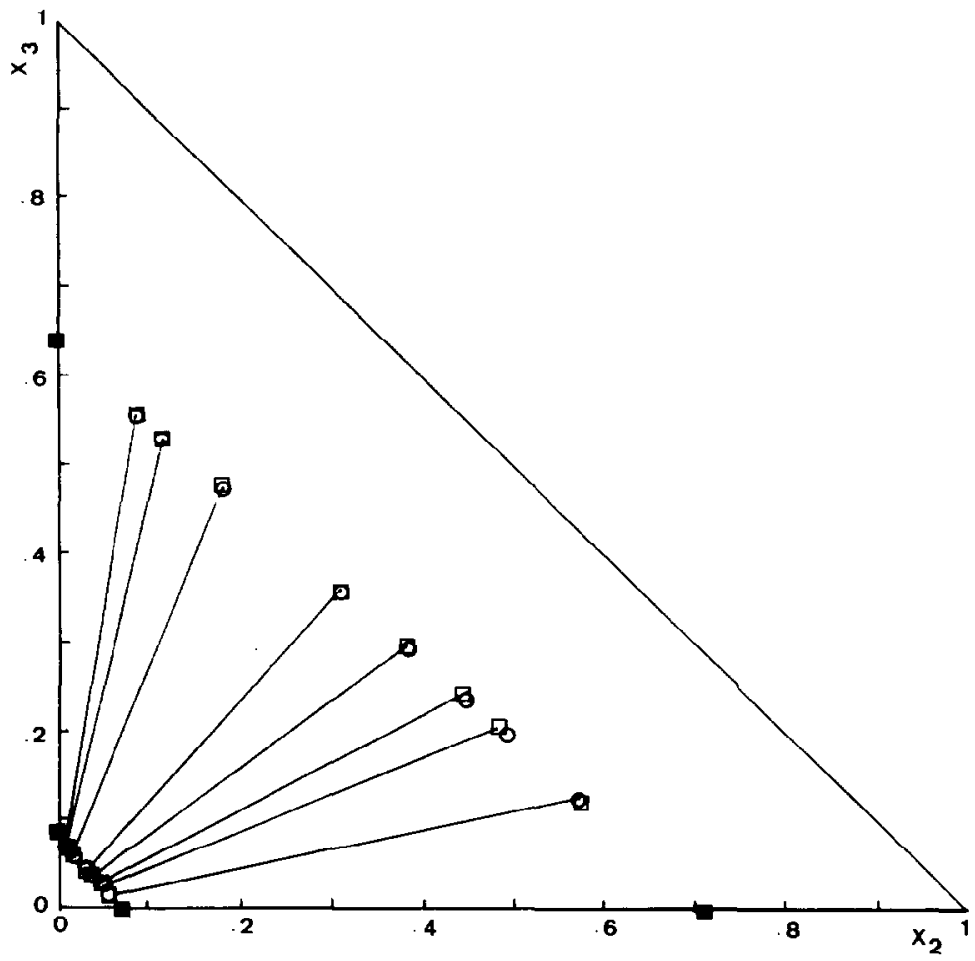

Fig. 6. Liquid-liquid equilibrium diagram for PFMCH-1-heptene-n-heptane at $288.15 \mathrm{~K}$. Symbols as in Fig. 5. 


\section{LIST OF SYMBOLS}

A, B methods of correlation of ternary data (Table 6).

$b_{i j} \quad$ NRTL parameters, $\mathrm{K}$, where $b_{i j}=\left(g_{i j}-g_{j j}\right) / R$

$c_{i j} \quad$ UNIQUAC parameters, $\mathrm{K}$, where $c_{i j}=\left(u_{i j}-u_{j j}\right) / R$

$g_{i j}, u_{i j}$ measures of the interaction energy between molecules $i$ and $j$

$x_{i j} \quad$ molar fraction of component $i$ in phase $j$

$X_{i j} \quad$ weight fraction of component $i$ in phase $j$

$U_{i j} \quad$ measure of the interaction energy between groups $i$ and $j$

$\alpha_{i j} \quad$ non-randomness NRTL parameter

\section{ACKNOWLEDGEMENTS}

The authors express their gratitude to the Instituto Nacional de Investigação Cientifica, which through the C.P.Q. (Universidade Técnica de Lisboa) and C.Q.P.A. (Universidade do Minho) supported this work.

The computing facilities offered by Centro de Informática (I.S.T.) are also gratefully acknowledged.

\section{REFERENCES}

Abrams, D.S. and Prausnitz, J.M., 1975. Statistical thermodynamics of multicomponent liquid mixtures: a new expression for the excess Gibbs energy of partly or completely miscible systems. AIChE J., 21: 116.

Bernardo-Gil, G.S. and Soares, L.J.S., 1988. Mutual binary solubilities: perfluoromethylcyclohexane/hydrocarbons. Fluid Phase Equilibria, 41: 205.

Renon, H. and Prausnitz, J.M., 1968. Local composition in thermodynamic excess functions for liquid mixtures. AIChE J., 14: 135.

Soares, L.J.S., Ashton, N.P. and Ellis, S.R.M., 1974. Prediction of multicomponent liquid equilibria data. Proc. Int. Solvent Extr. Conf., Lyon, France, 1974, Vol. 2, p. 1813. 